\title{
Fully mobilizing host defense: Building better vaccines
}

\author{
Syamal Raychaudhuri and Kenneth L. Rock ${ }^{1 *}$ \\ Corixa Corporation, Seattle, WA $98104 .{ }^{1}$ Department of Pathology, University of Massachusetts Medical Center, Worcester, MA 01655. \\ ${ }^{*}$ Corresponding author (e-mail: kenneth.rock@banyan.ummed.edu).
}

Received 11 March 1998; accepted 30 September 1998

\begin{abstract}
Developments in methods for identifying antigens from infectious agents and cancers has provided exciting new opportunities in prevention and treatment through vaccination. In many of these situations, however, traditional immunization techniques do not stimulate protective immunity because they fail to fully mobilize the appropriate immune responses. This limitation, together with new insights into the underlying mechanism of immune responses, has spurred development of several new approaches for vaccine delivery. We discuss some of the current efforts being developed to provide effective vaccine delivery systems.
\end{abstract}

Keywords: immunization, cyctotoxic T lymphocytes, adjuvant, microsphere

Vaccines and immunotherapies that provide protection against tumors have long been sought by researchers and oncologists because they have the potential to be much more effective, with fewer side effects, than conventional therapies ${ }^{1}$. In addition, there remains a need to protect against many pathogenic organisms against which vaccines are suboptimal or unavailable ${ }^{2,3}$. For tumor immunotherapy, the development of successful vaccines requires the identification of cellular antigens that are associated primarily with tumor cells. For infectious diseases, it is critical to identify antigens that are associated with various aspects of infection (entry, replication, and progression). In both cases, the antigens must be delivered in such a manner as to produce the appropriate immune response to control the growth of tumor or eradicate the infectious disease. While there has been considerable progress in techniques to identify antigens $s^{4,5}$, the traditional methods for delivering antigens are, in many cases, crude and inadequate.

Immunization with antigens alone often elicits weak or no immunity. Better immune responses can be elicited if antigens are administered in combination with adjuvants, which are immunostimulating agents, such as killed bacteria ${ }^{6}$. However, many adjuvants produce undesirable side effect, such as severe inflammation, that have precluded their human use. In fact, the only adjuvant that is currently approved for use in man is alum (aluminum hydroxide gel), which is a relatively weak potentiator of immune responses. Most of the adjuvants that have been tested preclinically have been discovered empirically and their mechanism of action is poorly understood. In addition, preclinical studies have shown that most conventional adjuvants support the generation of some kinds of immune responses but fail to elicit other important arms of the immune response such as cytotoxic T lymphocytes ${ }^{7}$.

The mechanisms by which the immune system controls disease include the induction of neutralizing antibodies and the generation of T-cell responses, including $\mathrm{T}$ helper $\left(\mathrm{T}_{\mathrm{H}}\right)$ cells and cytotoxic $\mathrm{T}$ lymphocytes (CTLs). For diseases caused by some viruses, such as polio and hepatitis, antibodies provide protection by preventing the virus from infecting cells $s^{8,9}$. Similarly, antibodies protect against some bacteria, such as pneumococci and staphylococci, by recruiting bactericidal mechanisms and neutralizing bacterial toxins ${ }^{10} . \mathrm{T}_{\mathrm{H}}$ cells also contribute to resistance against bacterial and viral diseases by producing cytokines and other bioactive molecules that cause inflammation and stimulate antibody, macrophage, and CTL responses ${ }^{11}$. Traditional vaccines and adjuvants stimulate antibody and, to varying degrees, $\mathrm{T}_{\mathrm{H}}$ cell responses and thereby provide protection against these diseases.

In contrast, antibody and $\mathrm{T}_{\mathrm{H}}$ cell responses do not eliminate most cancer or virally infected cells. In these situations protection is provided by CTLs, which kill the diseased cells ${ }^{12-15}$. Unfortunately, most conventional vaccines, which are composed of inactivated pathogens or their subunits, fail to elicit CTL responses ${ }^{16-18}$, and this has been a major limitation in the development of immunotherapies against viral diseases and cancer. Some of the reasons for the lack of CTL stimulation by conventional vaccines has been elucidated and a number of strategies are being pursued to circumvent these limitations (Table 1). This review will focus on advances in our understanding of how antigens stimulate CTL responses and the evolving strategies to elicit CTL responses.

\section{Antigen display}

In order to stimulate $\mathrm{T}$ lymphocyte responses, peptide fragments from antigens contained in a vaccine must first be bound to peptide binding receptors (major histocompatibility complex [MHC] class I and II molecules) that display the antigenic peptides on the surface of antigen presenting cells (APCs) ${ }^{19-21}$. T lymphocytes produce an antigen receptor that they use to monitor the surface of APCs for the presence of foreign peptides. The antigen receptors on $\mathrm{T}_{\mathrm{H}}$ cells recognize antigenic peptides bound to MHC class II molecules whereas the receptors on CTLs react with antigens displayed on class I molecules.

In addition to recognizing foreign antigens, $\mathrm{T}$ cells often need additional stimulation to become fully activated ${ }^{22}$. These additional signals are delivered through other receptors (e.g., CD28 and CD40L) on the T cell that interact with ligands (e.g., B7 and CD40) present on professional APCs, such as dendritic cells and macrophages, but which are absent from most other cells. These professional APCs traffic to lymphoid organs (the location where immune responses are initiated) where they present antigens very efficiently and deliver all required activation signals to $\mathrm{T}$ cells $\mathrm{s}^{23-25}$. Therefore, for vaccines to be effective, antigens contained in the vaccine mixture must be acquired and displayed by professional APCs. Dendritic cells are believed to be the most potent APCs for 
Table 1. Approaches to vaccine delivery.

\begin{tabular}{|c|c|c|c|}
\hline Approach & Antigen system & Type of response & Limitations \\
\hline \multirow[t]{5}{*}{ Infectious delivery } & $V_{\text {accinia }}^{28-30}$ & CTL, $T_{H}$, and antibody & Vaccinia response; potential pathogen especially in immunodeficiency \\
\hline & Adenovirus $^{31,32}$ & CTL, $\mathrm{T}_{\mathrm{H}}$, and antibody & Adenovirus response; potential pathogen especially in immunodeficiency \\
\hline & Salmonella ${ }^{33}$ & Weak CTL & $\begin{array}{l}\text { Unsuitable for systemic immunity; potential pathogen especially in } \\
\text { immunodeficiency }\end{array}$ \\
\hline & Listeria $^{34}$ & CTL, $\mathrm{T}_{\mathrm{H}}$, and antibody & Potential pathogen especially in immunodeficiency \\
\hline & $\mathrm{BCG}^{35,36}$ & CTL, $\mathrm{T}_{\mathrm{H}}$, and antibody & Antigen loss in vivo; potentially unsafe in immunosuppressed individuals \\
\hline \multirow[t]{2}{*}{$\begin{array}{l}\text { DNA and RNA } \\
\text { delivery }\end{array}$} & $\begin{array}{l}\text { Eukaryotic expression } \\
\text { plasmids }^{39-41}\end{array}$ & CTL, $\mathrm{T}_{\mathrm{H}}$, and antibody & $\begin{array}{l}\text { Potential insertional mutagenesis of host DNA; stimulation of antinucleic } \\
\text { acid antibody (single stranded); need for multiple injections }\end{array}$ \\
\hline & $\mathrm{RNA}^{42,43}$ & CTL, $\mathrm{T}_{\mathrm{H}}$, and antibody & Instability of the RNA; potential contamination with retroviral RNA component \\
\hline \multirow[t]{7}{*}{$\begin{array}{l}\text { Noninfectious } \\
\text { delivery }\end{array}$} & $\begin{array}{l}\text { Peptide conjugated } \\
\text { to lipid moiety }{ }^{44,45}\end{array}$ & CTL & $\begin{array}{l}\text { Utility and consistency with whole protein unknown; } \mathrm{T}_{H} \text { induction unknown; } \\
\text { knowledge of HLA type/subtype and epitope sequence are required; } \\
\text { need for multiple peptides in vaccine; cost }\end{array}$ \\
\hline & Peptide plus GM-CSF ${ }^{51}$ & $\mathrm{~T}_{\mathrm{H}}$ & Consistency of GM-CSF as an adjuvant for other peptides is not known \\
\hline & ISCOM, QS21 $1^{52-54}$ & CTL, $\mathrm{T}_{\mathrm{H}}$, and antibody & Potential toxicity \\
\hline & Ribi Detox adjuvant ${ }^{55-56}$ & CTL, $\mathrm{T}_{\mathrm{H}}$, and antibody & Antigen to antigen variation with regard to CTL response is unclear \\
\hline & $\mathrm{AF}^{58}$ & $\mathrm{CTL}, \mathrm{T}_{\mathrm{H}}$, and antibody & Consistency of CTL with antigen to antigen is not known \\
\hline & $\begin{array}{l}\text { Particulate delivery } \\
\text { including VLP } \\
\text { i1-66,84,85,91-94 }\end{array}$ & $\mathrm{CTL}, \mathrm{T}_{\mathrm{H}}$, and antibody & $\begin{array}{l}\text { Consistency and strength of CTL response with antigen to antigen } \\
\text { to be determined }\end{array}$ \\
\hline & $\mathrm{HSP}^{71}$ & CTL & Consistency of CTL response with weak tumor antigens is not known \\
\hline
\end{tabular}

stimulating immune responses ${ }^{23-25}$ and some approaches that are being explored are either to immunize with dendritic cells exposed to antigen ex vivo or to target antigens into dendritic cells in vivo.

MHC class II molecules allow the immune system to provide surveillance for antigens that are present in the extracellular fluids ${ }^{26}$. These antigens are internalized into the endocytic compartments of APCs where they are hydrolyzed into peptides, some of which become bound to class II molecules (Fig. 1A).

In contrast, the MHC class I molecules display peptides from genes expressed inside the cell, thus allowing the immune system to monitor for the presence of foreign antigens such as those from viruses or tumors (Fig. 1B) ${ }^{20}$. The majority of these peptides are generated in the cytoplasm by the action of a proteolytic particle known as the proteasome ${ }^{20}$. They are then transferred into the endoplasmic reticulum where they are bound by newly synthesized class I molecules and transported to the cell surface. As most vaccine formulations are injected into the extracellular fluid, antigens present in these formulations are presented on class II molecules and thus stimulate $\mathrm{T}_{\mathrm{H}}$ cell responses. Because these antigens are contained in membrane-bound vesicles that do not allow the antigen to enter cytoplasmic compartment of the cell, they are unable to be presented on class I molecules and consequently fail to stimulate CTL responses ${ }^{27}$.

Although the mechanism of action of traditional adjuvants is poorly understood, they are thought to potentiate responses by several means, including inducing inflammatory responses, which upregulate or stimulate the de novo production of key molecules (e.g., cytokines, adhesion, and costimulatory proteins) that are necessary for the generation and amplification of immune responses $^{22-25}$. In addition, several adjuvants provide a depot of antigen that is thought to sustain the stimulation of immune responses and possibly to stimulate APCs to acquire more antigen. Because the antigen depot is extracellular, it is presented exclusively on class
A Dendritic Cells, Macrophages, and B cells $\mid$ B

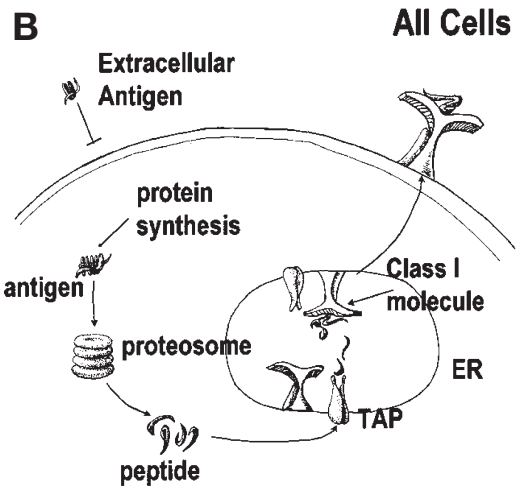

Figure 1. Antigen presenting pathways. (A) In the endoplasmic reticulum (ER), MHC class II molecules, a heterodimer composed of an alpha and beta chain, associate with the invariant chain, which prevents them from binding peptides. This complex is transported to endocytic molecules. MHC class II molecules can then bind peptides that are generated by proteolysis of proteins that are in endocytic compartments (e.g., from internalized proteins). The class II cases can recycle back into endosomes to acquire new peptides. This pathway is operative are hydrolyzed by proteasomes in the cytoplasm into oligopeptides, a fraction of which are transported into endoplasmic reticulum by TAP. Newly synthesized MHC class I molecules bind these peptides and transport them to the cell surface for display to CTL.

II molecules. Consequently, these kinds of adjuvants stimulate CD4-dependent responses, such as antibody responses, but do not generally induce CTL responses.

\section{Strategies to prime CTL responses with vaccines}

There are several strategies being pursued to enable vaccine antigen presentation on class I molecules and thereby elicit CTL immunity (Table 1). One approach introduces antigen genes into the host so that APCs will synthesize the antigen and therefore present antigenic peptides on class I molecules. Viral or bacterial vectors that invade the cytoplasm of cells have been used to introduce antigens into the APC. Vectors that have been used are vaccinia, the less invasive canary pox $^{28-30}$, adenovirus ${ }^{31,32}$, Listeria monocytogenes, Salmonella, or Mycobacterium bovis bacillus Calmette-Guérin 
$(B C G)^{33-36}$. These organisms have the potential to cause disease in humans; therefore, safety issues must be thoroughly addressed before such delivery systems can gain widespread acceptance ${ }^{37}$. An additional problem with this type of delivery is the production of neutralizing antibody responses to the vector, which may render further immunizations ineffective $e^{38}$. A promising alternative method is to inject plasmid expression vectors under conditions in which they are acquired, transcribed, and translated by host cells ${ }^{39-41}$. Similarly, the use of RNA as a vaccine delivery system for the induction of antigen-specific immunity has also been described $^{42,43}$. These latter two approaches allow repeated immunizations to be effective and are likely to be safer than viral vectors-although if the plasmid integrates into the host chromosomes it could disrupt or mutate host genes.

Another approach for inducing CTL is to bypass the antigen presenting pathway by immunizing with peptides in adjuvants or conjugated with lipids or with dendritic cells pulsed with peptide ex vivo $^{44-47}$. As small peptides can bind directly to class I molecules on the cell surface they can stimulate CTL responses when introduced into the extracellular fluids ${ }^{48}$. A limitation of this approach is that class I molecules vary from individual to individual and bind different peptides. Consequently, a single peptide will not protect all individuals. Another limitation is that peptide immunization is not always effective, possibly because there are relatively few class I molecules on cells that are available to bind peptides. For the induction of antigen-specific $\mathrm{T}_{\mathrm{H}}$ cells in vivo, peptides have been used with or without the addition of an adjuvant $t^{49-51}$. However, similar disadvantages, as discussed for CTL peptides, are also applicable.

Some approaches for eliciting CTL responses have been developed empirically. Adjuvants that that have been reported to elicit CTL responses include immunostimulating complexes (ISCOM), a mixture of Quil A and cholesterol that forms micelles ${ }^{52}$; QS21, an active component of Quil $\mathrm{A}^{53,54}$; emulsions with monophosphoryl lipid A, a detoxified form of lipopolysaccharide from Salmonella typhimurium; muramyl dipeptides, a minimal cell wall component from Mycobacterium ${ }^{55-57}$; and antigen formulation (AF), an oil-in-water emulsion composed of pluronic, squlane, and Tween ${ }^{58}$. Presumably some or all of these adjuvants promote MHC class I presentation by facilitating the delivery of antigens into the cytoplasm of cells, and this mode of action has been shown for ISCOMs ${ }^{59}$. Some of these preparations, like ISCOMs, QS21, and AF, contain detergents that might deliver antigens into cells by disrupting cellular membranes. However, the precise mechanism by which most of these preparations induce CTL responses is not defined.

Other antigen preparations that have been found to elicit CTLs are protein complexes that physically mimic viral particles. These have been generated from self-assembling proteins such as hepatitis B surface antigen, which assembles into $20 \mathrm{~nm}$ particles $\mathrm{s}^{60}$, and the yeast retrotransposon encoded protein $\mathrm{Ty}$, which assembles into virus-like particles (VLP) ${ }^{61}$. VLPs containing antigens have been produced by fusing Ty with the HIV gag protein p24, the V3 domain of the HIV envelope glycoprotein, multiple malaria epitopes, and other viral antigens ${ }^{62-66}$. Similarly, in some but not all reports, heat-inactivated viruses or even heat-aggregated proteins can prime CTL responses in vivo ${ }^{67,68}$. Yet another formulation that can induce CTLs are liposome-encapsulated antigens $s^{69,70}$. The precise mechanisms by which these various preparations induce CTL immunity are not fully resolved, although some may be able to deliver antigens to the cytoplasm by membrane fusion.

For tumor vaccines a promising empiric approach for eliciting CTL responses has been to immunize with heat shock proteins (HSPs) isolated from a tumor ${ }^{71}$. HSPs are intracellular chaperones that bind peptides and unfolded cellular proteins and therefore contain antigenic tumor peptides. Immunization with HSPs from tumors elicits antitumor immune responses. Moreover, immunization with protein antigens covalently bound to HSPs (e.g., as fusion proteins) can also elicit CTL responses ${ }^{72}$.

Many of these antigen formulations that elicit CTL may act in part via a newly discovered pathway of antigen presentation. The definition of this pathway and its underlying mechanism may allow for the rationale development and design of protein-based vaccines that elicit CTL and $\mathrm{T}_{\mathrm{H}}$ cell immunity.

\section{A novel pathway of MHC class I antigen presentation}

Although most cells are unable to present antigens from the extracellular fluids on class I molecules, macrophages and dendritic cells have this capability (Fig. 2) ${ }^{73-76}$. These cells internalize exogenous antigens into endocytic compartments and then transfer them to the cytoplasm by an unknown mechanism ${ }^{77}$. From this location the antigen is presented by the class I pathway in exactly the same manner as if it had been synthesized by the cell. It is cleaved into peptides by the proteasome, and these fragments are transported to class I molecules in the endoplasmic reticulum. Under some conditions, peptides that are generated in the endocytic compartment of these cells may also be presented on class I molecules ${ }^{78}$.

Although macrophages and dendritic cells are able to present soluble exogenous antigens on class I molecules they do this very inefficiently, requiring very high concentrations of protein ${ }^{79-81}$. Consequently, injection of soluble protein antigens generally fails to prime CTL immunity ${ }^{77}$. Therefore, for effective vaccine delivery it will be necessary to develop methods to target antigens into the exogenous pathway of the APCs more effectively. Both macrophages and dendritic cells (at some stages of development) internalize particles into large vacuoles called phagosomes or macropinosomes ${ }^{27,82,83}$ where exogenous antigens are transferred into the class I and class II pathways. Consequently, when exogenous antigens were attached to small particles they were presented 1000- to 10,000-fold more efficiently in the class I pathway than soluble antigen ${ }^{84,85}$. A similar enhancement in class II presentation was also achieved ${ }^{86}$.

This pathway may provide a unifying mechanism to explain the ability of many formulations of exogenous proteins that prime CTLs because a common feature of most of these preparations is that they are particulate in nature. This includes VLPs, liposomes, heat aggregated proteins, and ISCOMs. Moreover, light scattering analysis of emulsions such as AF reveals small micellar particles, and it has been observed that the potency of CTL responses is determined by the particle size distribution (unpublished data). Furthermore, depletion of phagocytes-key cells in the exogenous class I pathway-prevents the generation of CTLs to ISCOMs and QS21 (ref. 87). In addition, the HSPs seem to be presented exclusively on class I molecules of phagocytes ${ }^{71}$. If this concept is correct then it should be possible to design improved methods for targeting antigens into the MHC class I pathway. For example, in vitro studies have suggested that particles the size of viruses are less efficiently presented by macrophages and dendritic cells than larger particles (unpublished data).

The exogenous class I presentation pathway is of considerable interest for vaccine development because it provides a means of eliciting CTL immunity with antigens that are deposited into the extracellular fluids, where vaccine antigens are typically injected. Protein and peptide antigens can be used and presentation occurs without the need for agents that would break down the cell's membrane separating the extracellular compartment from the cytoplasm, a process that may be toxic to the cell. As the mechanism of antigen presentation is identical to that in viral infection or cancer, it provides a means to safely mimic the disease state. Finally, and of considerable importance, the antigens are being presented by precisely those cells (professional APCs) that are critical for initiating immune responses. 

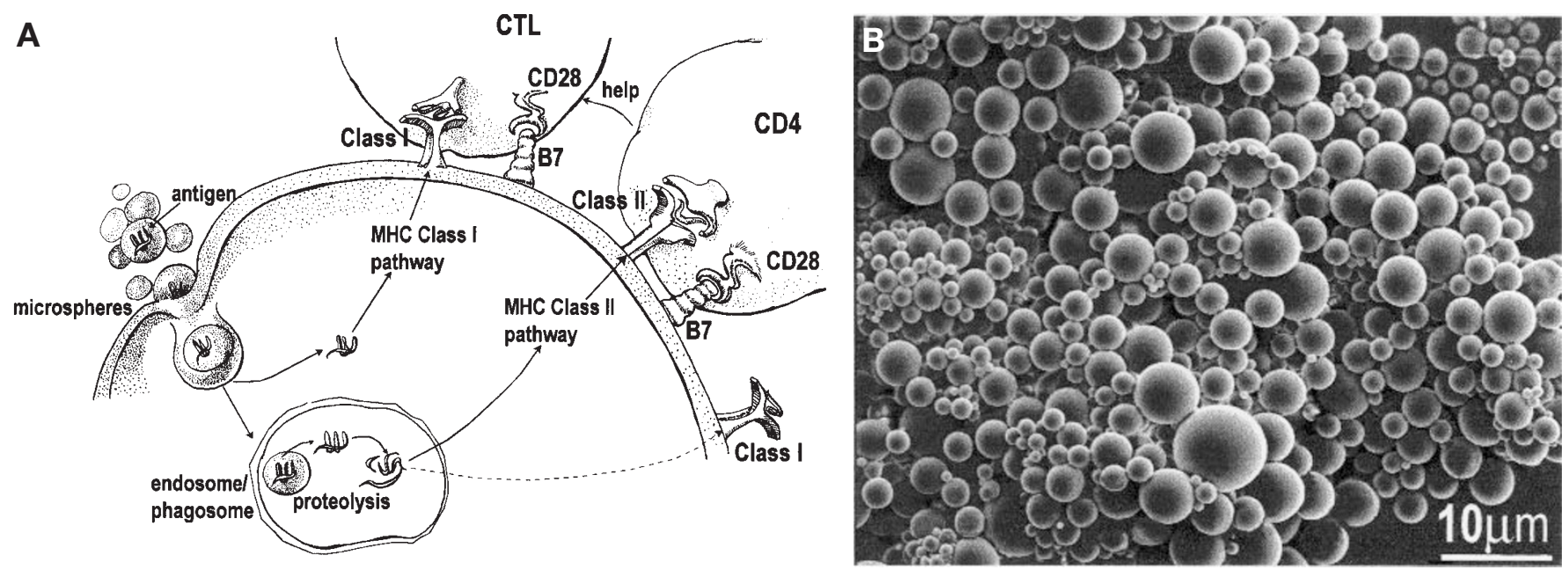

Figure 2. Presentation of exogenous antigens on MHC class I and II molecules. (A) In dendritic cells and macrophages, particulate antigens such as microspheres are internalized into phagosomes. A portion of the antigen is released into the cytoplasm where it becomes available to the MHC class I molecules. These APCs express all of the molecules, such as B7, needed to stimulate T cells and also may recruit CD4 T-cell help for CD8 T cells by bringing these two cells into close proximity. (B) A scanning electron micrograph of PLG microspheres. These preparations can efficiently deliver antigens into the exogenous class I and class II pathways and induce protective immune responses. Bar=10 microns.

\section{Prospects for vaccine delivery}

It is too early to tell which of the various approaches to elicit CTL immunity will be clinically useful. Their translation into clinical practice will depend on many variables including efficacy, ability to confer long-lasting immunity and/or to boost responses, safety, ease of manufacture and delivery, stability of the formulated vaccine, and cost. One approach that appears to satisfy most of the criteria for vaccine development is the use of particulate antigen delivery systems to introduce antigens into the endosomes and cytoplasm of cells and consequently into the class I and class II pathways. Particulate delivery technology should be safe, well tolerated, easily administered, and inexpensive. Moreover, the underlying mechanisms are understood and particularly attractive for vaccine delivery.

Proof of concept that this approach can be used to elicit CTL immunity and Thelper cell responses has been obtained by immunizing animals with exogenous antigens conjugated to micronsized latex or iron particles ${ }^{84,94}$. However, the composition of these particles is not optimal for use in humans. Therefore, the development of pharmaceutically acceptable particulate antigen delivery systems would appear to be a logical step in vaccine development.

Recent work in our laboratories has focused on the use of biodegradable poly-lactide-co-glycolide (PLG) microspheres to induce CTL responses in vivo. PLG microspheres are appealing as a vaccine delivery vehicle due to the fact that they are biodegradable and biocompatible and have been used in humans, both as suture materials ${ }^{88}$ and in other controlled-release formulations ${ }^{89,90}$. Antigens in PLG microspheres are protected from degradation by extracellular proteolytic enzymes. In addition, the rate of antigen release from microspheres can be controlled by altering the polymer composition, thereby allowing prolonged exposure of the immune system to the encapsulated antigen, with the possibility that a "single-shot" vaccine formulation may stimulate long-lasting humoral and cellular immunity. It has been previously reported that PLG microspheres are capable of inducing humoral immune responses against encapsulated ovalbumin and other antigens $^{50,91-94}$.

We have observed that PLG microspheres, between 1 and 10 $\mu \mathrm{m}$ in diameter, can efficiently deliver antigens into the class I MHC pathway of macrophages and dendritic cells via a TAPdependent mechanism. Moreover they are capable of stimulating strong CTL immunity in vivo. These results indicate that antigens released from the PLG microspheres into the extracellular fluids are not responsible for immune induction, as larger particles, which are not taken up by APCs, cannot prime CTL response in vivo. Relatively low doses of antigen (approximately $1 \mu \mathrm{g})$ are required to elicit these responses and, importantly, responses are generated to weakly antigenic (subdominant) regions of the antigen. The antigen particles are effective when injected subcutaneously, which is a simple and clinically acceptable route of immunization. A single injection of relatively small amounts of the particulate antigen in saline is able to elicit robust immune responses (unpublished data). This is in contrast to many other approaches in which antigens must be formulated in adjuvants that induce inflammatory responses and consequently may limit their use in humans. Moreover, microspheres can prime CTL responses in immunodeficient animals that lack CD4 T cells ${ }^{95}$.

PLG microspheres also elicit in vivo CTL responses to weak 'self' tumor antigens such as a P1A peptide ${ }^{96}$, without additional adjuvants (unpublished observation). These data contrast with results in which P1A-specific CTLs could only be generated using P1A-producing tumor cells transfected with B7.1 or interleukin-12 (IL-12) (refs. 97 and 98). It is possible that the full-length P1A antigen, containing both CTL and $\mathrm{T}_{\mathrm{H}}$ epitopes, will offer even stronger priming when encapsulated into PLG microspheres. However, a single injection of the P1A peptide encapsulated in PLG microspheres was adequate to protect mice against challenge with P815 tumor cells. This result is very encouraging as the P815 tumor is known to grow very aggressively.

We speculate that the ability of these microspheres to elicit strong immune responses even with low amounts of antigen and to weakly immunogenic epitopes is due to their efficient targeting of antigen into the most potent APCs (e.g., dendritic cells) for initiating immune responses. We further speculate that these preparations do not require adjuvants and can activate CTLs without T-cell help because the professional APCs express all the costimulatory and adhesion molecules necessary to stimulate immune responses. Although adjuvants are not required for these preparations, their inclusion may further boost responses. For this purpose there are now many well defined immunostimulants that could potentially be useful. 


\section{The use of immunoregulatory molecules as adjuvants}

The cloning and characterization of many immunoregulatory molecules such as cytokines and other receptor ligands is providing opportunities to manipulate immune responses with biologically active molecules. These molecules might be used as well-defined molecular adjuvants to generate stronger immunity or to alter the kind of immune responses. Because this is an important set of tools that could play an important role in future vaccine formulations, we describe the concepts and some of the current applications; however, an exhaustive review is beyond the scope of this paper.

Cloned cytokines have the advantage that they are well defined and could be used to selectively augment different steps in the generation of immune responses. Some factors, such as granulocytemacrophage colony-stimulating factor (GM-CSF), Flt3L, interferon- $\gamma$ (IFN- $\gamma$ ), and IL-12 (refs. 99-104), stimulate the growth or activity of APCs. Other factors, such as B7, IL-2, and IL-15 (refs. 105-110), stimulate the activation and growth of T lymphocytes. Some factors, such as IL- 4 , IFN- $\gamma$, and IL-12, can alter the kinds of cytokines produced by $\mathrm{T}$ lymphocytes and consequently their effector function (e.g., causing $\mathrm{T}$ cells to differentiate into IFN$\gamma$-producing inflammatory $\mathrm{TH}_{1}$ cells or IL-4-producing regulatory $\mathrm{TH}_{2}$ cells); this is important because in some cases $\mathrm{TH}_{1}$ responses are protective whereas $\mathrm{TH}_{2}$ responses exacerbate disease ${ }^{109,110}$. In principle, these factors could be combined with any antigen delivery system to improve immune responses qualitatively or quantitatively. They will not, however, allow antigen preparations that fail to be presented on class I molecules to elicit CTLs.

Proof of principle that coadministration of cytokines or other immunoregulatory molecule in combination with antigen can enhance immunity has come from studies in which tumor immunity in mice has been achieved through injection of tumor cells that have been genetically modified to secrete cytokines. There have also been some studies in which either plasmids or viral vectors that encode immunoregulatory molecules have been administered in combination with antigen. In various studies IL-2, IL-3, IL-4, IL-6, IL-10, IL-12, GM-CSF, IFN- $\gamma$, tumor necrosis factor- $\alpha$, Flt3L, and $B 7^{99-110}$ molecules have been shown to augment responses. Most studies to date have administered single cytokines, and it is possible that mixtures of cytokines will have additive effects as they have very different mechanisms of action (see above). Two cytokines that have shown effects in multiple studies are GM-CSF and IL-12. IL-12 is reported to augment antibody, CD4, and CTL responses. One of its well-characterized effects is to promote the differentiation of CD4 lymphocytes into $\mathrm{TH}_{1}$ cells. These cells produce cytokines such as IFN- $\gamma$ and IL-2, but not IL-4 and IL-10, and consequently they are particularly effective at inducing inflammation, activating macrophages and dendritic cells, and generating CTL. GM-CSF has been effective in inducing immune responses to several, but not all, tumors.

Controlled delivery of cytokines will be of importance to their use in vaccination protocols. Many of these agents have very short half-lives in vivo and may cause side effects if given at high doses systematically. These limitations may be circumvented through methods that allow sustained local release, such as encapsulation in microsphere delivery systems or transfer of cytokine genes in vivo. An alternative approach may be the use of agents that induce cytokine production at the site of injection, which is almost certainly how some traditional adjuvants function.

With the rapid progress in the characterization of microbial genes, it has become possible to identify molecules that trigger the release of cytokines. These molecules may be able to replace crude, inactivated whole microbes that have been used in traditional adjuvants. Such agents may have longer half-lives in vivo than cytokines and may stimulate cytokine release at the site of injection, circumventing some of the issues involved in the use of cytokines as vac- cine adjuvants. One example of such a molecule is Leif (Leishmania elongation initiation factor) derived from Leishmania major ${ }^{111}$. This protein upregulates the expression of B7 costimulatory molecules on antigen presenting cells, stimulates the production of IL-12 from human peripheral blood mononuclear cells and induces IFN$\gamma$ release from natural killer cells.

A very different strategy to boost immunity is based on the fact that immune responses are normally attenuated through the action of a number of negative regulatory receptors such as CTL antigen4 (CTLA-4) and fas. Accordingly, blocking the action of these receptors may lead to a response of greater magnitude and duration. Support for this concept has come from experiments in which antibodies against CTLA- 4 boosted the immune response to tumors ${ }^{112}$.

Cytokines and other immunoregulatory molecules could be used in principle to modify immune responses with many different vaccine methods including the particulate antigen delivery systems. This may be particularly useful in immunocompromised patients such as those with cancer or HIV, as supraoptimal immune response may be needed to provide sterilizing immunity.

Understanding the underlying mechanisms involved in the presentation of antigens and the generation of T-cell immune responses should allow the rational design of better vaccines and immunotherapies. We now understand some of the limitations of current vaccine technologies, and there are many different approaches to circumvent these limitations, including antigen delivery systems that elicit CTL responses. However, more work is needed to fully understand which of these approaches will be most effective and have an adequate safety profile for clinical use.

\section{Acknowledgments}

We thank Hang Fang, Rui Sun, and Jim Klaniecki for performing studies described herein and Mark Johnson for Fig. 2B; Paul Sleath for careful review of the manuscript; and Wendy Dale and Karen Kinch for helping with the manuscript preparation. This work was supported in part by an SBIR grant to Corixa Corporation and grants to K.L.R. from the NIH.

1. Vincent, T.D., Hellman, S., and Rosenberg S.S. (eds.). Biologic therapy of cancer. J.B. Lippincott Company, Philadelphia, PA.

2. Bloom, B. and Zinkernagel, R. 1996. Immunity to infection. Curr. Opin. Immunol. 8:465-466.

3. Woodrow, G.C. 1997. An overview of biotechnology as applied to vaccine development, pp. 25-34, in New generation vaccines; second edition. Levine, M.M., Woodrow, G.C., Kaper, J.B., and Cobon, G.S. (eds.). Marcel Dekker, New York.

4. Boon, T. and Old, L.J. 1997. Cancer tumor antigens. Curr. Opin. Immunol. 9:681-683.

5. Rosenberg, S.A. 1995. The development of new cancer therapies based on the molecular identification of cancer regression antigens. Cancer J. Sci. Am. 1:90.

6. Hunter, R.L., Olsen, M.R., and Bennett, B. 1995. Copolymer adjuvants and titermax, pp. 51-94, in The theory and practical application of adjuvants. Stewart-Tull, D.E.S. (ed.). John Wiley and Sons, Chichester, England.

7. Allsopp, C.E., Plebanski, M., Gilbert, S., Sinden, R.E., Harris, S., Frankel, G. et al. 1996. Comparison of numerous delivery systems for the induction of cytotoxic $T$ lymphocytes by immunization. Eur. J. Immunol. 8:1951-1959.

8. Reynolds, H.Y. 1988. Immunoglobin $\mathrm{G}$ and its function in the human respiratory tract. Mayo. Clin. Proc. 63:161-174.

9. Schwartz, J.S. 1982. Pneumococcal vaccine: clinical efficacy and effectiveness. Ann. Intern. Med. 96:208-220.

10. Teng, N.N.H., Kaplan, H.S., Herbert, J.M., Moore, C., Douglas, H., Wunderlich, A. et al. 1985. Protection against gram-negative bacteremia and endotoxemia with human monoclonal IgM antibodies. Proc. Natl. Acad. Sci. USA 82:1790-1794.

11. Constant, S.L. and Bottomly, K. 1997. Induction of Th1 and Th2 CD4+ T cell responses: the alternative approaches. Annu. Rev. Immunol. 15:297-322.

12. Lerner, R.A., Ginsberg, H.S., Chanock, R.M., and Brown, F. (eds.).Vaccines 89: modern approaches to new vaccines including prevention of AIDS. Cold Spring Harbor Laboratory Press, Cold Spring Harbor, New York.

13. Engers, H.D., Lahaye, T., Sorenson, G.D., Sorenson, G.D., Glasebrook, A.L., Horvath, C. et al. 1984. Functional activity in vivo of effector T cell populations.J. Immunol. 133:1664-1670.

14. McMichael, A.J., Gotch, F.M., Nobel, G.R., and Beare, P.A. 1980. Cytotoxic T-cell immunity to influenza. N. Engl. J. Med. 309:13-17.

15. Yee, C., Riddell, S.R., and Greenberg, P.D. 1997. Prospects for adoptive T cell therapy. Curr. Opin. Immunol. 9:705-708.

16. Rock, K.L. 1996. A new foreign policy: MHC class I molecules monitor the outside world. Immunol. Today 17:131-138.

17. Jondal, M., Schirmbeck, R., and Reimann, J. 1996. MHC Class I-restricted CTL responses to exogenous antigens. Immunity 5:295-302. 
18. Raychaudhuri, S. and Morrow, W.J. 1993. Can soluble antigens induce CD8+ cytotoxic T-cell responses? A paradox revisited. Immunol. Today 14:344-348.

19. Pamer, E. and Cresswell, P. 1998. Mechanisms of MHC class I-restricted antigen processing. Annu. Rev. Immunol. 16:323-358.

20. York, I.A. and Rock, K.L. 1996. Antigen processing and presentation by the class I major histocompatibility complex. Annu. Rev. Immunol. 14:369-396.

21. Germain, R.N., Castellino, F., Han, R., Reis, E., Sousa, C., Romagnoli, P. et al. 1996. Processing and presentation of enocytically acquired protein antigens by MHC class II and class I molecules. Immunol. Rev. 151:5-30.

22. Chambers, C.A. and Allison, J.P. 1997. Co-stimulation in T-cell responses. Curr. Biol. 9:396-404.

23. Hart, D.N.J. 1997. Dendritic cells: Unique leukocyte populations which control the primary immune response. Blood 90:3245-3287.

24. Cella, M., Sallusto, F., and Lanzavecchia, A. 1997. Origin, maturation and antigen presenting function of dendritic cells. Curr. Opin. Immunol. 9:10-16.

25. Banchereau, J. and Steinman, R.M. 1998. Dendritic cells and the control of immunity. Nature 392:245-252.

26. Germain, R.N. 1997. T-cell signaling: the importance of receptor clustering. Curr. Biol. 7:R640-R644.

27. Watts, C. 1997. Capture and processing of exogenous antigens for presentation on MHC molecules. Annu. Rev. Immunol. 15:821-850.

28. Moss, B. 1991. Vaccinia virus: a tool for research and vaccine development. Science 252:1662-1667.

29. Borysiewicz, L.K., Fiander, A., Nimako, M., Man, S., Wilkinson, G.W., Westmoreland, D. et al. 1996. A recombinant vaccinia virus encoding human papillomavirus types 16 and $18, \mathrm{E} 6$ and E7 proteins as immunotherapy for cervical cancer. Lancet 347:1523-1527.

30. Kwong, Y.T., Zaremba, S., Nieroda, C.A., Zhu, M.Z., Hamilton, J.M., and Schlom, J. 1995. Generation of human cytotoxic T cells specific for human carcinoembryonic antigen epitopes from patients immunized with recombinant vaccinia-CEA vaccine. J. Natl. Cancer Inst. 87:982-990.

31. Chen, P.W., Wang, M., Bronte, V., Zhai, Y., Rosenberg, S.A., and Restifo, N.P. 1996. Therapeutic antitumor response after immunization with a recombinant adenovirus encoding a model tumor-associated antigen. J. Immunol. 156:224-231.

32. Rodrigues, E.G., Zavala, F., Eichinger, D., Wilson, J.M., and Tsuji, M. 1997. Single immunizing dose of recombinant adenovirus efficiently induces CD8+ T cellmediated protective immunity against malaria. J. Immunol. 158:1268-1274.

33. Sadoff, J.C., Ballou, W.R., Baron, L.S., Majarian, W.R., Brey, R.N. et al. 1988. Oral salmonella typhimurium vaccine expressing circumsporozoite protein protects against malaria. Science 240:336-338.

34. Schafer, R., Portnoy, D.A., Brassell, S.A., and Paterson, Y. 1992. Induction of a cellular immune response to a foreign antigen by a recombinant Listeria monocytogenes vaccine. J. Immunol. 149:53-59.

35. Aldovini, A. and Young, R.A. 1991. Humoral and cell-mediated immune responses to live recombinant BCG-HIV vaccines. Nature 351:479-482.

36. Stover, C.K., de la Cruz, V.F., Fuerst, T.R., Burlein, J.E., Benson, L.A., Bennett, L.T. et al. 1991. New use of BCG for recombinant vaccines. Nature 351:456-460.

37. Guillaume, J.C., Saiag, P., Wechsler, J., Lescs, M.C., and Roujeau, J.C. 1991. Vaccinia from recombinant virus expressing HIV genes. Lancet 337:1034-1035.

38. Glorioso, J.C. 1996. Improving vectors. Gene Ther. 3:467-469.

39. Donnelly, J.J., Ulmer, J.B., Shiver, J.W., and Liu, M. DNA vaccines. 1997. Annu. Rev. Immunol. 15:617-618.

40. Robinson, H.L. and Torres, C.A. 1997. DNA vaccines. Semin Immunol. 5:271-283.

41. Johnston, S.A. and Barry, M.A. 1997. Genetic to genomic vaccination. Vaccine 15:808-809.

42. Boczkowski, D., Nair, S.K., Snyder, D., and Gilboa, E. 1996. Dendritic cells pulsed with RNA are potent antigen-presenting cells in vitro and in vivo. J. Exp. Med. 184:465-472.

43. Conry, R.M.J., Lo Buglio, A.F., Wright, M., Sumerel, L., Pike, M.J., Johanning, F. et al. 1995. Characterization of a messenger RNA polynucleotide vaccine vector. Cancer Res. 55:1397-1400.

44. Stauss, H.J., Davies, H., Sadovnikova, E., Chain, B., Horowitz, N., and Sinclair, C. 1992. Induction of cytotoxic T lymphocytes with peptides in vitro: identification of candidate T-cell epitopes in human papilloma virus. Proc. Natl. Acad. Sci. USA 89:7871-7875.

45. Deres, K., Schild, H., Wiesmuller, K.H., Jung, G., and Rammensee, H.G. 1989. In vivo priming of virus-specific cytotoxic $T$ lymphocytes with synthetic lipopeptide vaccine. Nature 342:561-564.

46. Rock, K.L., Fleischacker, C., and Gamble, S. 1993. Peptide-priming of cytolytic T cell immunity in vivo using beta 2-microglobulin as an adjuvant. J. Immunol. 150:1244-1252.

47. Young, J.W. and Inaba, K. 1996. Dendritic cells as adjuvants for class I major histocompatibility complex-restricted antitumor immunity. J. Exp. Med. 183:7-11.

48. Rock, K.L., Rothstein, L., and Benacerraf, B. 1992. Analysis of the association of peptides of optimal length to class I molecules on the surface of cells. Proc. Natl. Acad. Sci. USA 89:8918-8922.

49. Cheever, M.A., Disis, M.L., Bernhard, H., Gralow, J.R., Hand, S.L., Huseby, E.S. et al. 1995. Immunity to oncogenic proteins. Immunol. Rev. 145:33-59.

50. Men, Y., Gander, B., Merkle, H.P., and Corradin, G. 1996. Induction of sustained and elevated immune responses to weakly immunogenic synthetic malarial peptides by encapsulation in biodegradable polymer microspheres. Vaccine 14:1442-1450.

51. Disis, M.L. and Cheever, M.A. 1997. Her-2/neu protein: a target for antigen specific immunotherapy of human cancer. Adv. Cancer Res. 71:343-371.

52. Takahashi, H., Takeshita, T., Morein, B., Putney, S., Germain, R.N., and Berzofsky, J.A. 1990. Induction of CD8+ cytotoxic T cells by immunization with purified HIV1 envelope protein in ISCOMs. Nature 344:873-875.

53. Newman, M.J., Wu, J.Y., Gardner, B.H., Munroe, K.J., Leombruno, D., Recchia, J. et al. 1992. Saponin adjuvant induction of ovalbumin-specific CD8+ cytotoxic T lymphocyte responses. J. Immunol. 148:2357-2362.

54. Wu, J.Y., Gardner, B.H., Murphy, C.I., Seals, J.R., Kensil, C.R., Recchia, J. et al. 1992. Saponin adjuvant enhancement of antigen-specific immune responses to an experimental HIV-1 vaccine. J. Immunol. 148:1519-1525.

55. Ulrich, J.T. and Myers, K.R. 1994. Monophosphoryl lipid A as an adjuvant: past experience and new directions, pp. 495-524, in Vaccine design., Powell M.F. and Newman M.J. (eds.), Plenum Press, NY.

56. Mitchell, M.S., Harel, and W., Groshen, S. 1992. Association of HLA phenotype with response to active specific immunotherapy of melanoma. J. Clin. Oncol. 10:1158-1164.

57. Allison, A.C. and Byars, N.E. 1991. Immunological adjuvants: desirable properties and side effects. Mol. Immunol. 3:279-284.

58. Raychaudhuri, S., Tonks, M., Carbone, F., Ryskamp, T., Morrow, W.J., and Hanna, N. 1992. Induction of antigen-specific class I-restricted cytotoxic T cells by soluble proteins in vivo. Proc. Natl. Acad. Sci. USA 89:8308-8312.

59. van Binnendijk, R.S., van Baalen, C.A., Poelen, M.C., de Vries, P., Boes, J., Cerundolo, V. et al. 1992. Measles virus transmembrane fusion protein synthesized de novo or presented in immunostimulating complexes is endogenously processed for HLA class I- and class II-restricted cytotoxic T cell recognition. J. Exp. Med. 176:119-128

60. Schirmbeck, R., Thoma, S., and Reimann, J. 1997. Processing of exogenous hepatitis B surface antigen particles for Ld-restricted epitope presentation depends on exogenous beta2-microglobulin. Eur. J. Immunol. 27:3471-3484.

61. Layton, G.T., Harris, S.J., Myhan, J., West, D., Gotch, F., Hill-Perkins, M. et al. 1996. Induction of single and dual cytotoxic T-lymphocyte responses to viral proteins in mice using recombinant hybrid Ty-virus-like particles. Immunology 87:171-178.

62. Harris, S.J., Woodrow, S.A., Gearing, A.J., Adams, S.E., Kingsman, A.J., and Layton, G.T. 1996. The effects of adjuvants on CTL induction by V3:Ty-virus-like particles (V3-VLPs) in mice. Vaccine 14:971-976.

63. Conner, M.E., Zarley, C.D., Hu, B., Parsons, S., Drabinski, D., Greiner, S. et al. 1996. Virus-like particles as a rotavirus subunit vaccine. J. Infect. Dis. 174:S88-S92.

64. Greenstone, H.L., Nieland, J.D., de Visser, K.E., De Bruijn, M.L., Kirnbauer, R., Roden, R.B. et al. 1998. Chimeric papillomavirus virus-like particles elicit antitumor immunity against the E7 oncoprotein in an HPV16 tumor model. Proc. Natl. Acad. Sci. USA 95:1800-1805.

65. Sedlik, C., Saron, M., Sarraseca, J., Casal, I., and Leclerc, C. 1997. Recombinant parvovirus-like particles as an antigen carrier: a novel nonreplicative exogenous antigen to elicit protective antiviral cytotoxic T cells. Proc. Natl. Acad. Sci. USA 94:7503-7508

66. Gilbert, S.C., Plebanski, M., Harris, S.J., Allsopp, C.E., Thomas, R., Layton, G.T. et al. 1997. A protein particle vaccine containing multiple malaria epitopes. Nat. Biotechnol. 15:1280-1284.

67. Liu, T., Zhou, X., Orvell, C., Lederer, E., Ljunggren, H.G., and Jondal, M. 1995. Heat-inactivated sendai virus can enter multiple MHC class I processing pathways and generate cytotoxic T lymphocyte responses in vivo. J. Immunol. 154:3147-3155

68. Speidel, K., Osen, W., Faath, S., Hilgert, I, Obst, R., Braspenning, J. et al. 1997. Priming of cytotoxic $\mathrm{T}$ lymphocytes by five heat-aggregated antigens in vivo: conditions, efficiency, and relation to antibody responses. Eur. J. Immunol. 27:2391-2399

69. Collins, D.S., Findlay, K., and Harding, C.V. 1992. Processing of exogenous liposome-encapsulated antigens in vivo generates class I MHC-restricted $\mathrm{T}$ cell responses. J. Immunol. 148:3336-3341.

70. Nair, S., Zhou, F., Reddy, R., Huang, L., and Rouse, B.T. 1992. Soluble proteins delivered to dendritic cells via $\mathrm{pH}$-sensitive liposomes induce primary cytotoxic $T$ lymphocyte responses in vitro. J Exp. Med. 175:609-612.

71. Suto, R. and Srivastava, P.K. 1995. A mechanism for the specific immunogenicity of heat shock protein-chaperoned peptides. Science 269:1585-1588.

72. Suzue, K., Zhou, X., Eisen, H.N., and Young, R.A. 1997. Heat shock proteins as vehicles for antigen delivery into the major histocompatibility complex class I presentation pathway. Proc. Natl. Acad. Sci. USA 94:13146-13151.

73. Rock, K.L., Gamble, S., and Rothstein, L. 1990. Presentation of exogenous antigen with class I major histocompatibility complex molecules. Science 249:438-446.

74. Debrick, J.E., Campbell, P.A., and Staerz, U.D. 1991. Macrophages as accessory cells for class I MHC-restricted immune responses. J. Immunol. 147:2846-2851.

75. Denkers, E.Y., Gazzinelli, R.T., Hieny, S., Caspar, P., and Sher, A. 1993. Bone marrow macrophages process exogenous toxoplasma gondii polypeptides for recognition by parasite-specific cytolytic T lymphocytes. J. Immunol.150:517-526.

76. Rock, K.L., Rothstein, L., Gamble, S., and Fleischacker, C. 1993. Characterization of antigen-presenting cells that present exogenous antigens in association with class I MHC molecules. J. Immunol. 150:438-446.

77. Kovacsovics-Bankowski, M., and Rock, K.L. 1995. A phagosome-to-cytosol pathway for exogenous antigens presented on MHC class I molecules. Science 267:243-246.

78. Harding, C.V. and Geuze, H.J. 1993. Antigen processing and intracellular traffic of antigens and MHC molecules. Curr. Opin. Cell Biol. 5:596-605.

79. Grant, E.P. and Rock, K.L. 1992. MHC Class I-restricted presentation of exogenous antigen by thymic antigen-presenting cells in vitro and in vivo. J. Immunol. 148:13-18.

80. Norbury, C.C., Hewlett, L.J., Prescott, A.R., Shastri, N., and Watts, C. 1995 Class I MHC presentation of exogenous soluble antigen via macropinocytosis in bone marrow macrophages. Immunity 3:783-791.

81. Reise-Sousa, C. and Germain, R.N. 1995. Major histocompatibility complex class I presentation of peptides derived from soluble exogenous antigen by a subset of cells engaged in phagocytosis. J. Exp. Med. 182:841-852. 
82. Stahl, P.D. and Ezekowitz, R.A. 1998. The mannose receptor is a pattern recognition receptor involved in host defense. Curr. Opin. Immunol. 10:50-55.

83. Metalay, J.P. and Steinman, R.M. 1989. Control of the immune response at the level of antigen-presenting cells: a comparison of the function of dendritic cells and B lymphocytes. Adv. Immunol. 47:45-116.

84. Kovacsovics-Bankowski, M., Clark, K., Benacerraf, B., and Rock, K.L. 1993. Efficient major histocompatibility complex class I presentation of exogenous antigen upon phagocytosis by macrophages. Proc. Natl. Acad. Sci. USA 90:4942-4946.

85. Harding, C.V. and Song, R. 1994. Phagocytic processing of exogenous particulate antigens by macrophages for presentation by class I MHC molecule. J. Immunol. 153:4925-4933.

86. Vidard, L., Kovacsovics-Bankowski, M., Kraeft, S.K., Chen, L.B., Benacerraf, B., and Rock, K.L. 1996. Analysis of MHC class II presentation of particulate antigens of B lymphocytes. J. Immunol. 156:2809-2818.

87. Jia-Yan, W., Gardner, B.H., Kushner, N.N., Pozzi, L.M., Kensil, C.R., Cloutier, P.A. et al. 1994. Accessory cell requirements for saponin adjuvant-induced class MHC antigen-restricted cytotoxic T-lymphocytes. Cell Immunol.154:393-406.

88. Wise, D.L., Fellman, T.D., Sanderson, J.E., Wentworth, R.L., and Gregoriadis, G. (eds.). 1997. Drug carriers in biology and medicine. Academic Press, New York.

89. Moritera, T., Ogura, Y., Yoshimura, N., Honda, Y., Wada, R., Hyon, S.H. et al. 1992. Biodegradable microspheres containing adriamycin in the treatment of proliferative vitreretinopathy. Invest. Ophthalmol. Vis. Sci. 33:3125.

90. Rafferty, D.E., Elfaki, M.G., and Montgomery, P.C. 1996. Preparation and characterization of a biodegradable microparticle antigen/cytokine delivery system. Vaccine 14:532.

1. Marx, P.A., Compans, R.W., Gettie, A., Staas, J.K., Gilley, R.M., Mulligan, M.J. et al. 1993. Protection against vaginal SIV transmission with microencapsulated vaccine. Science 260:1323-1327.

92. Cahill, E.S., O'Hagan, D.T., Illum, L., Barnard, A., Mills, K.H., and Redhead, K. 1995. Immune responses and protection against Bordetella pertussis infection after intranasal immunization of mice with filamentous haemagglutinin in solution or incorporated in biodegradable microparticles. Vaccine 13:455-462.

93. Vordermeier, H.M., Coombes, A.G., Jenkins, P., McGhee, J.P., O'Hagan, D.T. et al. 1995. Synthetic delivery system for tuberculosis vaccines: immunological evaluation of the M. tuberculoisis $38 \mathrm{kDa}$ protein entrapped in biodegradable PLG microparticles. Vaccine 13:1576-1582.

94. Partidos, C.D., Vohra, P., Anagnostopoulou, C., Jones, D.H., Farrar, G.H., and Steward, M.W. 1996. Biodegradable microparticles as a delivery system for measles virus cytotoxic T cell epitopes. Mol. Immunol. 33:485-491.

95. Rock, K.L. and Clark, K. 1996. Analysis of the role of MHC class II presentation in the stimulation of cytotoxic T lymphocytes by antigens targeted into the exogenous antigen-MHC class I presentation pathway. J. Immunol. 156:3721-3726.

96. Van den Eynde, B., Lethe, B., Van Pel, A., De Plaen, E., and Boon, T. 1991. The gene coding for a major tumor rejection antigen of tumor P815 is identical to the normal gene of syngeneic DBA/2 mice. J. Exp. Med. 173:1373-1384.

97. Li, Y., Hellstrom, K.E., Newby, S.A., and Chen, L. Costimulation by CD48 and B7-
1 induces immunity against poorly immunogenic tumors. 1996. J. Exp. Med. 183:639-644.

98. Fallarino, F., Uyttenhove, C., Boon, T., and Gajewski, T.F. 1996. Endogenous IL12 is necessary for rejection of P815 tumor variants in vivo. J. Immunol. 156:1095-1100.

99. Schmidt-Wolf, G. and Schmidt-Wolf, I.G.H. 1995. Cytokines and clinical gene therapy. Eur. J. Immunol. 25:1137-1140.

100. Dranoff, G., Jaffee, E., Lazenby, A., Golumbek, P., Levitsky, H., Brose, K. et al. 1993. Vaccination with irradiated tumor cells engineered to secrete murine granulocyte-macrophage colony-stimulating factor stimulates potent, specific, and long-lasting anti-tumor immunity. Proc. Natl. Acad. Sci. USA. 90:3539-3543

101. Pulendran, B., Lingappa, J., Kennedy, M.K., Smith, J., Tepee, M., Rudensky, A. et al. 1997. Developmental pathways of dendritic cells in vivo. Distinct function, phenotype, and localization of dendritic cell subsets in FLT3 ligand-treated mice. J. Immunol. 159:2222-2231.

102. Biron, C.A. and Gazzinelli, R.T. 1995. Effects of IL-12 on immune responses to microbial infections: a key mediator in regulating disease outcome. Curr. Opin. Immunol. 7:485-496.

103. O'Garra, A. 1998. Cytokines induce the development of functionally heterogeneous T helper cell subsets. Immunity. 8:275-283.

104. Powrie, F. and Coffman, R.L. 1993. Cytokine regulation of T-cell function: potential for therapeutic intervention. Trends Pharmacol. Sci. 14:164-168.

105. Thompson, C.B. 1995. Distinct roles for the costimulatory ligands B7-1 and B72 in T helper cell differentiation? Cell. 81:979-982.

106. O' Garra, A. 1997. Interleukin-12 and up: functions of T helper subsets resulting from differential cytokine production. Res. Immunol. 148:413-416.

107. Bronte, V., Tsung, K., Rao, J.B., Chen, P.W., Wang, M., Rosenberg, S.A. et al. 1995. II-2 enhances the function of recombinant poxvirus-based vaccines in the treatment of established pulmonary metastases. J. Immunol. 154:5282-5292.

108. Giovarelli, M., Musiani, P. Modesti, A., Dellabona, P. Casorati, G., Allione, A. et al. 1995. Local release of II-10 by transfected mouse mammary adenocarcinoma cells does not suppress but enhances antitumor reaction and elicits a strong cytotoxic lymphocyte and antibody-dependent immune memory. J. Immunol. 155:3112-3123.

109. Mosmann, T.R. and Sad, S. 1996. The expanding universe of T-cell subsets: Th1, Th2 and more. Immunol. Today. 17:138-146.

110. Mosmann, T.R., Li, L., Hengartner, H., Kagi, D., Fu, W., and Sad, S. 1997. Differentiation and functions of T cell subsets. Ciba. Found Symp. 204:148-154.

111. Probst, P., Skeiky, Y., Steeves, M., Gervassi, A., Grabstein, K.H., and Reed, S.G. 1997. A leishmania protein that modulates interleukin (IL)-12, IL-10 and tumor necrosis factor-a production and expression of B7-1 in human monocytederived antigen-presenting cells. Eur. J. Immunol. 27:2634-2642.

112. Kwon, E.D., Hurwitz, A.A., Foster, B.A., Madias, C., Feldhaus, A.L., Greenberg, N.M. et al. 1997. Manipulation of T cell costimulatory and inhibitory signals for immunotherapy of prostate cancer. Proc. Natl. Acad. Sci. USA 94:8099-8103. 